\title{
Latissimus dorsi avulsion, with coupled teres major injury, in a professional football goalkeeper: case report
}

Mathew Prior M. Sports Physio, B. Physio (Hons)

Physiotherapist, Leading Edge Physical Therapy, Adelaide United FC, Adelaide, Australia

Jason Collins M. Sports Physio, B. Physio (Hons)

Physiotherapist, Adelaide United FC, Adelaide, Australia

Richard Pope MBBS, FRACS, FA OrthA

Orthopaedic Surgeon, Wakefield Orthopaedic Clinic, Adelaide, Australia

\section{ABSTRACT}

Significant upper limb injuries are rare in professional football [soccer]. Latissimus dorsi avulsion injury is particularly rare in sport of all types, with limited published information informing optimal management. A 35 year-old male professional football goalkeeper sustained, via a non-contact ball throwing mechanism, a latissimus dorsi avulsion and partial teres major tendon tear during competitive matchplay. He undertook a conservative rehabilitation programme, emphasising progressive mechanical loading, in order to return to full function and competition. The player successfully returned to unrestricted training at 32 days post-injury and returned to play at 38 days post-injury. At 12 months post-injury he had suffered no injury recurrence and remains playing at the same competition level. Latissimus dorsi avulsion is an uncommon injury, with accurate diagnosis requiring both a high level of clinical suspicion coupled with diagnostic imaging. Despite the severity, this injury may be amenable to conservative management in even elite athletes with high functional demands. The following case outlines such a management approach successfully utilised with a professional football goalkeeper.

Prior, M., Collins, J., Pope, R. (2018). Latissimus dorsi avulsion, with coupled teres major injury, in a professional football goalkeeper: case report. New Zealand Journal of Physiotherapy 46(3): 139-146. doi:10.15619/NZJP/46.3.06

Key words: Shoulder, Soccer, Rehabilitation, Tendon

\section{INTRODUCTION}

Whilst injuries are common in professional football [soccer], upper limb injuries are infrequent, with significant noncontact upper limb injuries rare (Carling, Orhant, \& LeGall, 2010; Ejnisman et al, 2016). Latissimus dorsi avulsion injury is particularly rare in sport of all types, with limited published information informing recognition and optimal management. This case report documents an unusual injury involving latissimus dorsi tendon avulsion, with combined teres major injury, in a professional footballer and the conservative management approach utilised to rehabilitate him to full function and competition. The patient provided informed consent for presentation of case information herein.

\section{CASE DESCRIPTION}

The player was a 35 year-old male, right-hand dominant goalkeeper, with over 17 years of professional playing experience. He was on no regular medication and was asymptomatic preceding injury.

He experienced acute right posterior shoulder pain following an overarm throw, occurring in the 25th minute of a domestic league match. He was unable to continue and thus removed from play. Acute sideline management consisted of sling immobilisation and ice application (15 minutes/hour) until conclusion of the match (Bleakley et al, 2011).

Relevant past history included bilateral articular-surface partial supraspinatus tendon tears, previously managed with ultrasound-guided subacromial corticosteroid injection and rotator cuff strengthening exercise. This had been asymptomatic for the previous 3 years.

Detailed testing was conducted post-match [Table 1, Figure 1], leading to initial hypothesis of latissimus dorsi and/or posterior rotator cuff musculotendinous strain. Sling immobilisation and regular ice application were continued, with diagnostic imaging arranged for the following day.

Table 1: Summary of initial post-match examination

\begin{tabular}{ll}
\hline Test & Findings \\
\hline Observation & Unremarkable \\
Sh AROM & $\begin{array}{l}\text { Grossly intact, but slow elevation } \\
\text { Pain HBB, EOR ER }\end{array}$ \\
RSC & Sh ER: R 4+/5 power (2/10 pain); L 5/5 \\
& Sh IR: R 5/5 power (6/10 pain); L 5/5 \\
& Sh Extension (30F): pain-inhibited \\
Palpation & Painful about area marked in Figure 1 \\
Special tests & Belly press: painful, nil lag \\
& HBB lift-off: painful, able to perform
\end{tabular}

Notes: Sh, shoulder; AROM, active range of movement; RSC, resisted static contraction; EOR, end of range; $E R$, external rotation; IR, internal rotation; $\mathrm{HBB}$, hand-behind-back 


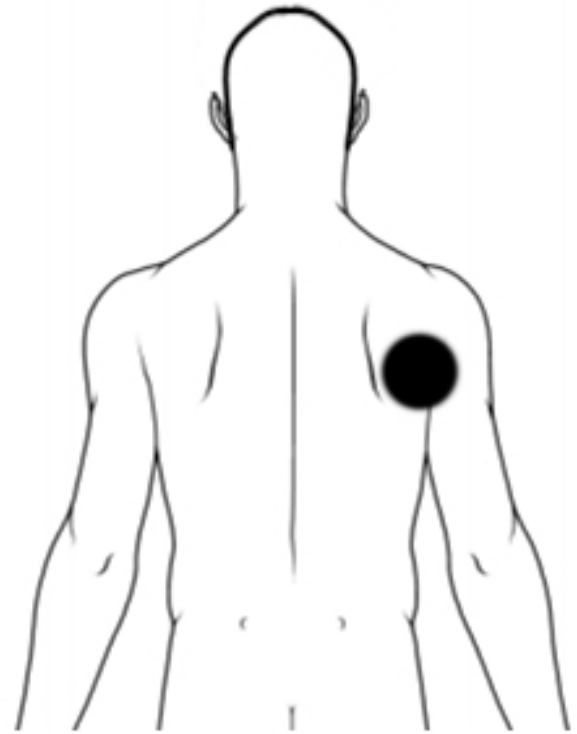

- Location of symptoms

\section{Figure 1: Body Chart}

Investigations

Ultrasound imaging was initially performed, which demonstrated no acute changes compared to previous studies. Given clinical suspicion of injury, Magnetic Resonance Imaging [MRI] was subsequently performed. This demonstrated fullthickness tear of the latissimus dorsi insertion, with $6 \mathrm{~mm}$ avulsion of the tendon from the anteromedial humeral cortex [Figure 2]. No marrow oedema within the proximal humerus or scapula, nor significant oedema extending into the latissimus dorsi muscle belly, was identified. Near-complete teres major tendon tear was also identified, with fluid tracking along the medial humerus and extending posteriorly deep to the posterior deltoid muscle.

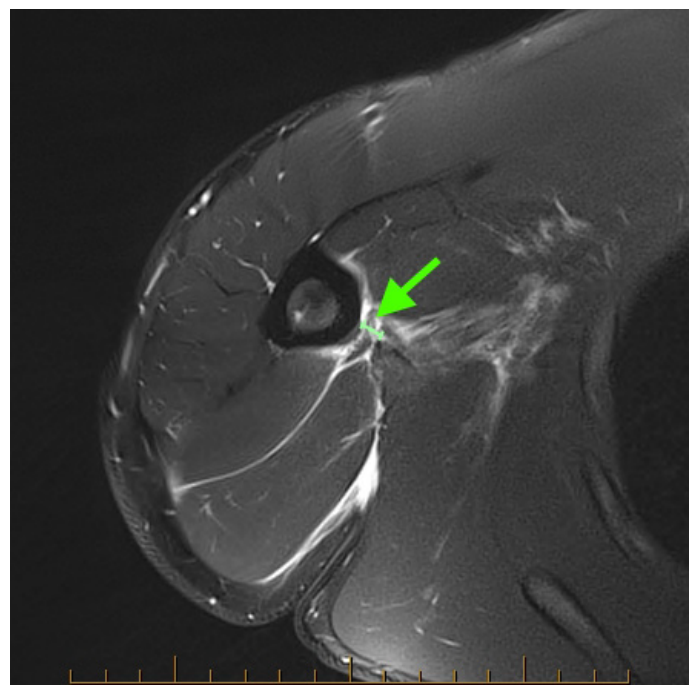

Figure 2: Magnetic Resonance Imaging of latissimus dorsi tendon lesion (arrow), with avulsion from anteromedial humeral cortex highlighted (line).
Due to the rare and significant nature of the injury, specialist orthopaedic opinion was sought. At this time, the player displayed full shoulder range of movement [ROM], intact axillary nerve function and reported significant reduction of pain. Due to signs of rapid clinical improvement and reported comparable outcomes of surgical and conservative management, recommendation was made to manage the player non-operatively (Schickendantz, Kaar, Meister, Lund, \& Beverley, 2009). A return to play timeframe of $4-6$ weeks was estimated based on previous case reports (Fysentzou, 2016; Maciel, Zogaib, de Castro Porchini, \& Ejnisman, 2015) and rate of clinical improvement thus far.

\section{Rehabilitation}

A progressive criterion-based rehabilitation programme was devised [Appendix 1], which was considered to give the best opportunity to safely expedite return to play if appropriate, based on successful completion of prerequisite phases.

Shoulder immobilisation was continued initially to protect the affected area, whilst minimising loss of general conditioning where possible. The player's usual pre-morbid lower limb resistance training exercises not involving weight holding (eg leg press, calf raise) were continued from day 3 post-injury, whilst stationary cycling was used to maintain aerobic fitness.

Expediting resumption of running and kicking loads was considered important to maintain football-specific conditioning; however, reproducing the athlete's pain was deemed likely with these activities due to their associated arm swing. In order to facilitate early resumption, player-rated pain score of 2/10 was defined as the threshold between 'acceptable' pain reasonably expected with activity, versus 'unacceptable' pain suggestive of excessive and potentially injurious tissue loading. This pain-monitoring approach has been successfully utilised in tenopathology management elsewhere (Littlewood, Malliaras, Mawson, May, \& Walters, 2013; Silbernagel, Thomee, Eriksson, \& Karlsson, 2007). However, lower pain thresholds were used in this case due to greater pathology severity.

Isotonic exercise (Phase 3) was commenced on successful completion of light isometric exercise, with inner- and midrange positions used initially to minimise excessive stretch on the musculotendinous unit. Commensurate with light resisted rehabilitation exercises in inner- and mid-range positions being performed, simple non-overhead/limited-reach catching drills were introduced at this time to maintain skilled task performance. Phase 4 exercises represented a progression of mechanical loading via both increase of resistance applied and work performed in outer-range positions of the musculotendinous unit. Similarly, fieldwork rehabilitation was progressed by progressing ball handling/catching drills into overhead positions. Overarm throwing was not permitted in this phase.

Upper limb plyometric and power tasks (Phase 5) were subsequently introduced; which represented not only increased mechanical load to develop musculotendinous capacity, but an essential rehabilitation task given the player's need to use his upper limbs in landing tasks and resisting high-speed shots. Example exercises utilised in all rehabilitation phases are listed in Appendix 2. As part of the introduction of power and plyometric 
tasks, controlled throwing and diving exercises were introduced in this phase under physiotherapist supervision. Goalkeeping drills involving diving were performed with coaching staff at a later stage (Phase 6), with throwing tasks still limited in both number and distance [Table 2].

In addition to successful completion of modified training and high-load rehabilitation exercise, shoulder extension strength values of $90 \%$ or greater compared to the player's unaffected side, as measured by handheld dynamometry, were used as a criterion for return to unrestricted training (Phase 7) [Table 3]. Successful completion of a minimum of one week's full unrestricted training was set as a criterion to achieve before return to play.

\section{Table 2: Fieldwork throwing programme}

$\frac{\text { Days post injury }}{17}$

18

19

20

21

22

23

24

25

26

27

28

29

30

31

32
Throwing programme

$2 \times 5$ reps, short, DA

Nil

$1 \times 5$ reps, medium, DA

$2 \times 5$ reps, short, DA

Nil

$1 \times 8$ reps, medium, DA

$2 \times 5$ reps, short, SA

$2 \times 5$ reps, short, SA

Nil

$1 \times 5$ reps, short, SA

$2 \times 5$ reps, medium, SA

$3 \times 3$ reps, short, DA

$3 \times 5$ reps, medium, SA

Nil

$3 \times 3$ reps, short, DA

$2 \times 3$ reps, medium, SA

$1 \times 3$ reps, long, SA

Nil

$3 \times 5$ reps, short, DA

$2 \times 3$ reps, medium, SA

$1 \times 3$ reps, long, SA

Nil

Return to full unrestricted training

Notes: Short, 0-15m; Medium, 15-30m; Long, 30+m; DA, double-arm; $\mathrm{SA}$, single-arm

\section{OUTCOMES}

The player returned to full unrestricted training 32 days postinjury and successfully completed a full competitive match at 38 days post-injury. He completed eight consecutive further competitive matches in the same season without issue, before transferring to another club at the end of the season. At 12 months post-injury, he remained participating regularly in the same professional league, reporting satisfaction with his level of shoulder function and no recurrence of injury.

\section{Table 3: Shoulder extension strength over time}

\begin{tabular}{lll}
\hline Days post injury & Sh $E\left(90^{\circ} \mathrm{F}^{\star}\right)(\mathrm{kg})$ & $\operatorname{ShE}\left(30^{\circ} \mathrm{F}^{*}\right)(\mathrm{kg})$ \\
\hline 14 & $18.0(75 \%)^{* *}$ & $16.0(76.19 \%)$ \\
19 & $23.0(85.82 \%)$ & $19.9(86.14 \%)$ \\
26 & $22.4(87.84 \%)$ & $22.1(87.00 \%)$ \\
31 & $25.0(98.03 \%)$ & $22.7(90.8 \%)$ \\
60 & $27.1(103.05 \%)$ & $22.7(96.19 \%)$ \\
\hline
\end{tabular}

Notes: Sh, shoulder; E, extension; F, flexion.

* Tested isometrically at $90^{\circ}$ and $30^{\circ}$ shoulder flexion positions.

** Percentage relative to unaffected limb in parentheses.

\section{DISCUSSION}

Few reports of latissimus dorsi tendon avulsion, with or without teres major involvement, exist, highlighting the rare nature of this injury. In a sporting context, the existing literature typically pertains to throwing or overhead athletes, notably baseball pitchers (Ellman et al, 2013; Nagda et al, 2011; Park, Lhee, \& Keum, 2008; Schickendantz et al, 2009). Whilst uncommon, the true incidence of injury may not be fully appreciated given the moderate functional limitations encountered in this and other reported cases (Fysentzou, 2016; Maciel et al. 2015). In the absence of imaging to confirm diagnosis, such limitations may be attributed to less significant pathology.

Latissimus dorsi is a powerful extensor, adductor and internal rotator of the shoulder, with an extensive origin about the thoracolumbar spine and iliac crest (Fysentzou, 2016; Henry \& Scerpella, 2000; Schickendantz et al, 2009). Fibres of latissimus dorsi traverse the axilla to insert into the proximal humerus at the lesser tuberosity and medial aspect of the bicipital groove (Fysentzou, 2016; Henry \& Scerpella, 2000; Schickendantz et al, 2009). Teres major performs similar functions and can have confluent fibres with latissimus dorsi at the humeral aspect (Maciel et al, 2015; Malcolm, Reinus, \& London, 1999).

Whilst both conservative and surgical management approaches have been described, insufficient evidence exists to define one as superior. It has been suggested that surgical management may be preferable in professional athletes owing to their greater functional demands and the potential for residual strength deficits with conservative management, however these concerns are not supported by the available literature (Ellman et al, 2013; Henry \& Scerpella, 2000; Le et al, 2009; Lim, Tilford, Hamersly, \& Sallay, 2006). Surgical management has been reported to typically result in return to full sporting function at 6 months (Ellman et al, 2013; Park et al, 2008), whereas with conservative management such timeframes have been reported to vary widely between five weeks and 10 months (Fysentzou, 2016; Schickendantz et al, 2009). 
Only two comparable injuries in football have previously been reported, both involving goalkeepers. Fysentzou (2016) described a complete latissimus dorsi myotendinous junction rupture caused by falling on an outstretched arm, with return to play at five weeks post-injury. Maciel et al (2015) reported a case of isolated teres major tendon rupture caused by overarm throwing; this athlete was able to complete the match in which the injury occurred, before subsequent return to play after 18 days. In both cases, athletes were conservatively managed with rehabilitation programmes consisting of progressive strengthening exercises and graded return to play (Fysentzou, 2016; Maciel et al, 2015). Both authors rate their outcomes as excellent, with no injury recurrence or functional limitation at 12-month follow-up (Fysentzou, 2016; Maciel et al, 2015). Repeat imaging to assess structural healing in both cases was either not performed or inadequately described (Fysentzou, 2016; Maciel et al, 2015).

Whilst conservative management programmes have resulted in favourable outcomes, the scarcity of injury and variation in reported protocols precludes consensus on optimal rehabilitation. The criterion-based rehabilitation programme presented in this case followed the principles of progressive mechanical loading in tenopathology (Cook \& Docking, 2015; Galloway, Lalley, \& Shearn, 2013; Kjaer, 2014) and examples from other conservatively managed tendon avulsion cases in professional football (Fysentzou, 2016; Gamradt et al, 2009; Maciel et al, 2015; Ueblacker, English, \& Mueller-Wohlfahrt, 2016). It is conceded that management principles utilised in this case derive heavily from published tendinopathy management approaches (Cook \& Docking, 2015; Galloway, Lalley, \& Shearn, 2013; Kjaer, 2014), which may not be fully appropriate in cases of tendon avulsion. Nonetheless, given the success of the application of progressive mechanical loading in this and other cases, we would contend at this time that it appears reasonable to apply such an approach. It is important that progressive loading does not merely refer to increased resistance of load. Application of load at differing tendon lengths and at differing speeds also represented higher loads in this case, influencing the elastic loading properties of the musculotendinous unit and restoring sport-specific function (Galloway et al, 2013).

The potential for structural healing of the avulsed tendon is considered to exist with conservative management, as demonstrated in cases of lower limb tendon avulsion in professional football (Gamradt et al, 2009; Ueblacker et al, 2016). However, this was demonstrated at 12 weeks post-injury via MRI, but not at six weeks (Ueblacker et al, 2016). As such, it is considered unlikely that full structural healing occurred before return to play in this case, with transfer of the player to another club precluding repeat imaging to assess structural healing following extended rehabilitation. Improved dynamometry scores and restoration of sport-specific function in this case are likely in part attributable to the development of synergistic muscles and their function; most notably posterior deltoid and long head of triceps, which are synergists of forceful shoulder extension (Kronberg, Nemeth, \& Brostrom, 1990; Landin \& Thompson, 2011).

Restoration of functional strength was considered integral and informed rehabilitation progressions. Resisted shoulder extension strength was used as a measure of function of the affected musculotendinous units, with restoration of at least $90 \%$ strength relative to the unaffected side serving as one criterion to progress to return to play. This figure was based on similar values being used in return to play decision-making with other common football-related musculoskeletal injury (Heiderscheit, Sherry, Silder, Chumanov, \& Thelen, 2010; Kyritsis, Bahr, Landreau, Miladi, \& Witvrouw, 2016; Mendiguchia \& Brughelli, 2011; van der Horst, Backx, Goedhart, \& Huisstede, 2017). Given the player's dominant throwing arm was affected, which would reasonably be expected to be stronger than his non-dominant arm, it can be argued that this value may have been set too low. Nonetheless, the player tolerated full training and matchplay at this level.

Factors contributing to injury remain speculative. Similar to this case, in a series of 10 latissimus dorsi and teres major tears in professional baseball pitchers, all players were asymptomatic preceding injury (Schickendantz et al, 2009). In both previously documented cases in football goalkeepers, players were aged over 30 years (Fysentzou, 2016; Maciel et al, 2015). As such, older age, via either age-related degenerative changes in the musculotendinous unit or greater cumulative exposure to potentially injurious forces, may be a contributor (Fysentzou, 2016; Maciel et al, 2015). Competition level, with respect to the generation of and exposure to higher forces in professional sport, may be a relevant consideration (Schickendantz et al, 2009).

The relevance of past history of shoulder pain and supraspinatus pathology in this athlete as a potential contributor is unclear. Previous injury may have affected shoulder kinematics leading to altered latissimus dorsi and teres major demands, but this remains speculative. Poor-quality tendon structure and failed repair processes are well documented in tenopathology with chronic exposure to excessive loading (Cook \& Purdam, 2009; Scott, Backman, \& Speed, 2015), however the lack of preceding symptoms diminishes this theory. Past history of corticosteroid injection about the shoulder is noted and whilst its potentially deleterious effect on tendon structure is well-documented, this is considered an unlikely contributor in this case. This is due to the differing location of ultrasound-guided administration (subacromial space) and the lack of repeat corticosteroid injections which may otherwise result in adverse events via cumulative dosage (Coombes, Bisset, \& Vicenzino, 2010; Fredberg, 1997; Orchard, 2008).

Significant discrepancy between ultrasound and MRI findings existed. Whilst ultrasound examinations are highly operatordependent, the anatomical depth of the injury, accentuated by habitus and significant muscular bulk of the player's shoulder, were likely contributors. Whilst ultrasound is still considered valuable in musculoskeletal assessment, particularly with respect to its ability to dynamically identify functional as well as morphological abnormality, the aforementioned case highlights its limitations (Kijowski \& De Smet, 2006). It also serves as a reminder for clinicians to consider repeat or alternate investigations if there is a high level of clinical suspicion despite negative imaging results (Kijowski \& De Smet, 2006). 


\section{CONCLUSION}

This case documents unusual injury to the latissimus dorsi and teres major tendons in a professional football goalkeeper and the progressive, criterion-based conservative management programme used to successfully rehabilitate him to full function and competition. Whilst rarely documented, clinicians dealing with overhead and/or throwing athletes should be aware of this pathology when assessing the athlete with acute onset posterior shoulder pain, particularly in light of the relatively mild functional limitations and potential for false negative imaging results with differing modalities.

\section{KEY POINTS}

1. Latissimus dorsi avulsion is a rare injury in sport; particularly football [soccer]

2. Initial symptoms may be relatively mild, incommensurate with injury severity.

3. The potential for false negatives with imaging highlights the limitations of different modalities.

4. Despite injury severity, conservative management may be appropriate, even in a high-level overhead athlete.

\section{DISCLOSURES}

The authors affirm that they have no financial affiliation or involvement with any commercial organisation that has a direct financial interest in any matter included in this manuscript, nor any other financial, professional or personal conflict of interest affecting the writing or publication process. No funding was obtained for this study.

\section{ADDRESS FOR CORRESPONDENCE}

Mathew Prior, Leading Edge Physical Therapy, 76A Kensington Rd, Rose Park SA 5067, Australia. Telephone: +61 883646800. Email: mathew.prior@gmail.com.

\section{REFERENCES}

Bleakley, C.M., Glasgow, P.D., Phillips, N., Hanna, L., Callaghan, M.J., Davison, G.W. et al. (2011). Management of acute soft tissue injury using Protection Rest Ice Compression and Elevation: Recommendations from the Association of Chartered Physiotherapists in Sports and Exercise Medicine (ACPSM). London: ACPSM.

Carling, C., Orhant, E., \& LeGall, F. (2010). Match injuries in professional soccer: inter-seasonal variation and the effects of competition type, match congestion and positional role. International Journal of Sports Medicine, 31(4), 271-276.

Cook, J.L., \& Docking, S.I. (2015). Defining 'tissue capacity': a core concept for clinicians. British Journal of Sports Medicine, 49(23), 1484-1485.

Cook, J.L., \& Purdam, C.R. (2009). Is tendon pathology a continuum? A pathology model to explain the clinical presentation of load-induced tendinopathy. British Journal of Sports Medicine, 43(6), 409-416.

Coombes, B.K., Bisset, L., \& Vicenzino, B. (2010). Efficacy and safety of corticosteroid injections for management of tendinopathy: a systematic review of randomised controlled trials. Lancet, 376(9754), 1751-1767.

Ejnisman, B., Barbosa, G., Andreoli, C.V., de Castro Porchini, A., Lobo, T., Zogaib, R., et al. (2016). Shoulder injuries in soccer goalkeepers: review and development of a FIFA 11+ shoulder injury prevention program. Open Access Journal of Sports Medicine, 7, 75-80. doi:10.2147/OAJSM/S97917.
Ellman, M.B., Yanke, A., Juhan, T., Verma, N.N., Nicholson, G.P., Bush-Joseph, $C$. et al. (2013). Open repair of an acute latissimus tendon avulsion in a Major League Baseball pitcher. Journal of Shoulder and Elbow Surgery, 22(7), e19-e23.

Fredberg, U. (1997). Local corticosteroid injection in sport: review of literature and guidelines for treatment. Scandinavian Journal of Medicine \& Science in Sports, 7(3), 131-139.

Fysentzou, C. (2016). Rehabilitation after a grade III latissimus dorsi tear of a soccer player. Journal of Back and Musculoskeletal Rehabilitation, 29(4), 905-916.

Galloway, M.T., Lalley, A.L., \& Shearn, J.T. (2013). The role of mechanical loading in tendon development, maintenance, injury, and repair. Journal of Bone and Joint Surgery America, 95A(17), 1620-1628.

Gamradt, S.C., Brophy, R.H., Barnes, R., Warren, R.F., Thomas Byrd, J.W., \& Kelly, B.T. (2009). Nonoperative treatment for proximal avulsion of the rectus femoris in professional American football. American Journal of Sports Medicine, 37(7), 1370-1374.

Heiderscheit, B.C., Sherry, M.A., Silder, A., Chumanov, E.S., \& Thelen, D.G. (2010). Hamstring strain injuries: recommendations for diagnosis, rehabilitation, and injury prevention. Journal of Orthopaedic and Sports Physical Therapy, 40(2), 67-81

Henry, J.C., \& Scerpella, T.A. (2000). Acute traumatic tear of the latissimus dorsi tendon from its insertion. A case report. American Journal of Sports Medicine, 28(4), 577

Kijowski, R., \& De Smet, A.A. (2006). The role of ultrasound in the evaluation of sports medicine injuries of the upper extremity. Clinics in Sports Medicine, 25(3), 569-590.

Kjaer, M. (2014). Throw away the anti-inflammatories \& start loading your damaged tendons: evidence into practice. Aspetar Sports Medicine Journal, 3(2), 390-393.

Kronberg, M., Nemeth, G., \& Brostrom, L.A. (1990). Muscle activity and coordination in the normal shoulder. An electromyographic study. Clinical Orthopaedics and Related Research, 257, 76-85.

Kyritsis, P., Bahr, R., Landreau, P., Miladi, R., \& Witvrouw, E. (2016). Likelihood of $A C L$ graft rupture: not meeting six clinical discharge criteria before return to sport is associated with a four times greater risk of rupture. British Journal of Sports Medicine, 50(15), 946-951.

Landin, D., \& Thompson, M. (2011). The shoulder extension function of the triceps brachii. Journal of Electromyography and Kinesiology, 21(1), 161165.

Le, H.B., Lee, S.T., Lane, M.D., Munk, P.L., Blachut, P.A., \& Malfair, D. (2009) Magnetic resonance imaging appearance of partial latissimus dorsi muscle tendon tear. Skeletal Radiology, 38(11), 1107-1110.

Lim, J.K., Tilford, M.E., Hamersly, S.F., \& Sallay, P.I. (2006). Surgical repair of an acute latissimus dorsi tendon avulsion using suture anchors through a single incision. American Journal of Sports Medicine, 34(8), 1351-1355.

Littlewood, C., Malliaras, P., Mawson, S., May, S., \& Walters, S. (2013). Development of a self-managed loaded exercise programme for rotator cuff tendinopathy. Physiotherapy, 99(4) 358-362

Maciel, R.A., Zogaib, R.K., de Castro Porchini, A., \& Ejnisman, B. (2015). Isolated rupture of teres major in a goalkeeper. BMJ Case Reports, Dec 23. doi:10.1136/bcr-2015-210524.

Malcolm, P.N., Reinus, W.R., \& London, S.L. (1999). Magnetic resonance imaging appearance of teres major tendon injury in a baseball pitcher. American Journal of Sports Medicine, 27(1), 98-100

Mendiguchia, J., \& Brughelli, M. (2011). A return-to-sport algorithm for acute hamstring injuries. Physical Therapy in Sport, 12(1), 2-14.

Nagda, S.H., Cohen, S.B., Noonan, T.J., Raasch, W.G., Ciccotti, M.G., \& Yocum, L.A. (2011). Management and outcomes of latissimus dorsi and teres major injuries in professional baseball pitchers. American Journal of Sports Medicine, 39(10), 2181-2186. 
Orchard, J. (2008). Which sports medicine conditions are NSAIDs and cortisone injections useful for? SportHealth, 26(2), 11-13.

Park, J.Y., Lhee, S.H., \& Keum, J.S. (2008). Rupture of latissimus dorsi muscle in a tennis player. Orthopedics, 31(10).

Schickendantz, M.S., Kaar, S.G., Meister, K., Lund, P., \& Beverley, L. (2009). Latissimus dorsi and teres major tears in professional baseball pitchers: a case series. American Journal of Sports Medicine, 37(10), 2016-2020.

Scott, A., Backman, L., \& Speed, C. (2015). Tendinopathy - update on pathophysiology. Journal of Orthopaedic and Sports Physical Therapy, 45(11), 833-841.

Silbernagel, K.G., Thomee, R., Eriksson, B.I., \& Karlsson, J. (2007). Continued sports activity, using a pain-monitoring model, during rehabilitation in patients with Achilles tendinopathy: a randomized controlled study. American Journal of Sports Medicine, 35(6), 897-906.

Ueblacker, P., English, B., \& Mueller-Wohlfahrt, H.W. (2016). Nonoperative treatment and return to play after complete proximal adductor avulsion in high-performance athletes. Knee Surgery, Sports Traumatology, Arthroscopy, 24(12), 3927-3933.

Van der Horst, N., Backx, F.J.G., Goedhart, E.A., \& Huisstede, B. (2017). Return to play after hamstring injuries in football (soccer): a worldwide Delphi procedure regarding definition, medical criteria and decisionmaking. British Journal of Sports Medicine, 51(22), 1583-1591. 


\section{PHASE 1 - IMMOBILISATION}

Goals: Prevent worsening of pathology

\begin{tabular}{|l|l|l|}
\hline Rehab & Fieldwork/Training & Key Criteria to Progress \\
\hline $\begin{array}{l}\text { Immobilisation (sling/relative rest) } \\
\text { LL exercise only }\end{array}$ & Nil & $\begin{array}{l}\text { No pain at rest } \\
\text { Minimum 1 week immobilisation }\end{array}$ \\
\hline
\end{tabular}

\section{PHASE 2 - ISOMETRIC LOADING}

Goals: Commence light shoulder/UL exercise; resume running within pain limits

\section{Rehab Exercise}

Isometric shoulder exercise

Light non-shoulder-specific UL strength

exercise (e.g. bicep, tricep)

\section{Fieldwork/Training}

Running/Agility: low-speed

Kicking: short-distance

\section{Key Criteria to Progress}

Full shoulder ROM

$<2 / 10$ pain with running/agility

No pain during isometric exercise

\section{PHASE 3 - ISOTONIC LOADING: Simple}

Goals: Commence simple isotonic shoulder exercise

\begin{tabular}{|l|}
\hline Rehab Exercise \\
\hline Isotonic shoulder exercise \\
(low resistance; inner/mid-range positions) \\
Catching drills (non-overhead)
\end{tabular}

\section{Fieldwork/Training}

Running/Agility: progress speed

Kicking: short-medium distance

Handling/ballwork: non-overhead

\section{Key Criteria to Progress}

$<2 / 10$ pain with resisted exercise

$<2 / 10$ pain with increased speed running/ agility

\section{PHASE 4 - ISOTONIC LOADING: Advanced}

Goals: Progress resistance of isotonic exercise and into outer-range (on-stretch) positions

\begin{tabular}{|l|l|}
\hline Rehab Exercise & Fieldwork/Training \\
\hline Isotonic shoulder exercise (increased & Running/Agility: progress speed $\geq$ \\
resistance; include outer-range positions) & $85 \%$ of player maximum \\
Body weight-resisted exercise & Kicking: long distance/goal kicks \\
(e.g. DA/SA push-up) & Handling/ballwork: include overhead \\
& positions at low intensity \\
\hline
\end{tabular}

Key Criteria to Progress

$<2 / 10$ pain with outer-range resisted exercise

Nil pain with simple overhead handling/ ballwork

\section{PHASE 5 - PLYOMETRICS + MODIFIED TRAINING}

Goals: Commence plyometric/power exercises, trial modified football training

\section{Rehab Exercise}

Continue isotonic shoulder exercise. Commence plyometric and power shoulder exercises

\section{PHASE 6 - MODIFIED TRAINING}

Goals: Complete modified football (non-rehab) training with minimal restrictions

\begin{tabular}{|c|c|c|}
\hline Rehab Exercise & Fieldwork/Training & Key Criteria to Progress \\
\hline $\begin{array}{l}\text { Continue shoulder exercise (isotonic } \\
\text { strength + plyometrics) }\end{array}$ & $\begin{array}{l}\text { Modified football training: } \\
\text { Limit throwing distance/repetition }\end{array}$ & $\begin{array}{l}\text { Strength: resisted extension } \geq 90 \% \text { vs } \\
\text { unaffected } \\
\text { Nil issues with modified training }\end{array}$ \\
\hline \multicolumn{3}{|l|}{ PHASE 7 - RETURN TO PLAY } \\
\hline \multicolumn{3}{|l|}{ Goals: Resume unrestricted training and RTP } \\
\hline Rehab Exercise & Fieldwork/Training & Key Criteria to Progress \\
\hline $\begin{array}{l}\text { Continue isotonic shoulder strength exercise } \\
\text { Suspend plyometric exercise due plyometric } \\
\text { tasks in full training }\end{array}$ & Full training & $\begin{array}{l}\text { Minimum } 1 \text { week full training without issue } \\
\text { before RTP }\end{array}$ \\
\hline \multicolumn{3}{|l|}{ Notes: } \\
\hline Return to play & Upper Limb & Lower Limb \\
\hline Double-arm & Single-arm & \\
\hline
\end{tabular}

\section{Key Criteria to Progress}

\begin{tabular}{l|l|l} 
Modified football training: No & Strength: resisted extension $\geq 85 \%$ vs
\end{tabular}

throwing or diving $\quad$ unaffected

Controlled throwing, diving/return to Nil pain with plyometric exercise

\begin{tabular}{l|l} 
feet with physio & Nil issues with modified training
\end{tabular} 


\section{APPENDIX 2: Example rehabilitation exercises by phase}

\begin{tabular}{|c|c|c|c|c|}
\hline Phase & \multicolumn{4}{|c|}{ Exercise } \\
\hline $\begin{array}{l}\text { Phase } 2 \\
\text { (Isometric loading) }\end{array}$ & \multicolumn{2}{|c|}{ 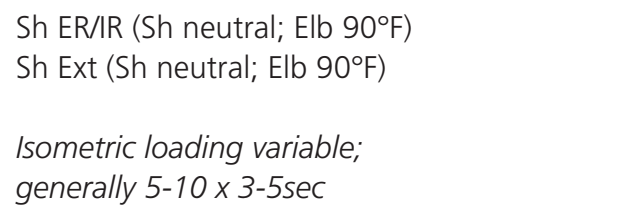 } & \multicolumn{2}{|c|}{$\begin{array}{l}\text { Sh Add (Sh neutral; Elb 90F) } \\
\text { Scapular retraction }\end{array}$} \\
\hline $\begin{array}{l}\text { Phase } 3 \\
\text { (Isotonic loading: simple) }\end{array}$ & \multicolumn{2}{|c|}{$\begin{array}{l}\text { TB IR/ER (Sh } 0^{\circ} \mathrm{F} \text {; Elb 90 } \mathrm{F} \text { ) } \\
\text { Closed chain MB circles on wall } \\
\text { Standing/inclined wall push-up } \\
\text { Side plank on elbow } \\
\text { Isotonic loading variable; } \\
\text { generally 2-3 } \times \text { 6-10 reps }\end{array}$} & \multicolumn{2}{|c|}{$\begin{array}{l}\left.\text { TB DA Row (Elb } 90^{\circ} \mathrm{F}\right) \\
\text { TB DA Low Row }\left(\operatorname{Sh} 45^{\circ} \rightarrow 0^{\circ} \mathrm{F}\right)\end{array}$} \\
\hline $\begin{array}{l}\text { Phase } 4 \\
\text { (Isotonic loading: } \\
\text { advanced) }\end{array}$ & \multicolumn{2}{|c|}{$\begin{array}{l}\text { Cable woodchop (DA } \rightarrow \text { SA) } \\
\text { Cable Shoulder ER/IR }\left(\mathrm{Sh} 0^{\circ} \mathrm{F}\right) \\
\left.\text { Cable Shoulder ER/IR (Sh } 90^{\circ} \mathrm{Abd}\right) \\
\text { Prone Push-up; push-up on bosu } \\
\text { Standing lat pulldown } \\
\text { Isotonic loading variable dependent on load; } \\
\text { generally } 3 \text { × 3-8 reps }\end{array}$} & \multicolumn{2}{|c|}{$\begin{array}{l}\text { SA Pectoral Fly } \\
\text { Side-plank on elbow } \\
\text { Side push-up } \\
\text { MB overhead raises (Sh F, F/Abd) } \\
\left.\text { SA Low Row ( } 45^{\circ} \mathrm{F} \rightarrow 0^{\circ} \mathrm{F}\right)\end{array}$} \\
\hline $\begin{array}{l}\text { Phase } 5 \\
\text { (Plyometrics/ } \\
\text { Power) }\end{array}$ & \multicolumn{2}{|c|}{$\begin{array}{l}\text { Push-up with clap } \\
\text { Push-up with lateral land off box } \\
\text { MB throw/catch vs rebounder } \\
\text { Plyometric/power loading variable; } \\
\text { generally } 1-3 \text { x 3-5 reps }\end{array}$} & \multicolumn{2}{|c|}{$\begin{array}{l}\text { SA standing lat pulldown - fast speed/low } \\
\text { resistance } \\
\text { DA standing row - fast speed/low resistance }\end{array}$} \\
\hline Phases 6-7 & \multicolumn{4}{|c|}{ Continue phase 4, 5 exercises } \\
\hline Notes: & & $\begin{array}{l}\text { Shoulder } \\
\text { Elbow } \\
\text { Theraband } \\
\text { Medicine Ball } \\
\text { External Rotation } \\
\text { Internal Rotation }\end{array}$ & $\begin{array}{l}\text { F } \\
\text { Abd } \\
\text { Add } \\
\text { Ext } \\
\text { DA } \\
\text { SA }\end{array}$ & $\begin{array}{l}\text { Flexion } \\
\text { Abduction } \\
\text { Adduction } \\
\text { Extension } \\
\text { Double-arm } \\
\text { Single-arm }\end{array}$ \\
\hline
\end{tabular}

